\title{
Physical plant design and engineering controls to reduce hospital-acquired infections
}

\author{
JM Conly $M D^{1}, B L$ Johnston $M^{2}$
}

T he importance of the environment as a reservoir for microorganisms implicated in disease transmission in the hospital setting has been increasingly recognized, especially with respect to dialysis units, ventilation in specialized areas, and the proper use of disinfectants (1). Inherent within the environmental setting is the importance of physical plant design. Several studies have underscored the importance of optimizing design standards to maximize patient and health care worker $(\mathrm{HCW})$ safety, including the prevention of hospitalacquired infections in patients (2-6). Ulrich et al (7) recently completed an evidence-based review, entitled 'The role of the physical environment in the hospital of the 21st century: A once-ina-lifetime opportunity', for the Center for Health Design in California (USA), which was funded by the Robert Wood Johnson Foundation. Ulrich and colleagues identified over 600 studies that examined the hospital environment and its effects on staff effectiveness, patient safety, patient and family stress, quality and costs. They suggested that one of the important elements in improving patient safety is the reduction of the risk of hospital-acquired infections through improved facility design.

Many examples of hospital-acquired infections that have impacted patient and HCW safety exist, including severe acute respiratory syndrome (SARS), multidrug-resistant tuberculosis, Clostridium difficile and infections caused by antibioticresistant organisms (AROs) (8-16). Zoutman et al (17) estimated that 220,000 health care-associated infections (HAIs), including 8000 deaths, occur each year in Canada. Recent outbreaks caused by SARS, vancomycin-resistant Enterococcus (VRE), methicillin-resistant Staphylococcus aureus (MRSA) and Clostridium difficile-associated disease (CDAD) have involved disease transmission not only among patients but also to HCWs and visitors (18-23). HAIs are major contributors to adverse events in health care, estimated to occur in $3.2 \%$ to $19.7 \%$ of all acute care admissions in Canada (24). The estimated annual cost of HAIs in the United States is US\$5 billion (25). In Canada, the costs associated with MRSA have been estimated to be $\$ 42$ to $\$ 59$ million dollars per annum (26). A 2003 modelling study (27) estimated that if MRSA and other resistant bacteria continue to increase in prevalence from current Canadian levels to those being reported in the United States, the added direct expenses in Canada would rise to between $\$ 104$ and $\$ 187$ million per annum, and the cost of precautions would increase to $\$ 157$ million per annum. Several studies (28-30) have concluded that one-third of adverse events (including HAIs) are preventable.
The costs associated with MRSA and VRE underestimate the amount of money health care facilities are spending to prevent the nosocomial transmission of these AROs. Outbreaks of MRSA in specific at-risk community populations (intravenous drug users, homeless patients, patients who are or who have recently been incarcerated) have added to the burden of hospitalized MRSA-positive patients (31). In Quebec, Montreal and Sherbrooke have reported rapid increases in the number of CDAD cases acquired through nosocomial transmission of this pathogen (32,33). This CDAD outbreak was caused by a pathogen that acquired a new virulence factor, resulting in increased patient morbidity and mortality, as well as the disruption of health care delivery in these two cities. In 2003, The Conference Board of Canada estimated that the impact of SARS was approximately $\$ 1$ billion to Toronto and $\$ 1.5$ billion to Canada (34).

Within the hospital setting, acquiring a specific organism and subsequent infection depends on many different factors. These factors may be related to the host, the microbe, the host-microbe interaction, the use of antimicrobials, the hostantimicrobial interaction, and the host environment. The host, the microbe, the type and duration of exposure of the host to the microbe within the environment and the interventions used to prevent the development of an infection all influence a patient's risk of acquiring a specific microbe and a subsequent nosocomial infection (35).

Specific host risk factors include the following: a high level of acuity of illness; a high level of immunosuppression; malnutrition; a history of frequent hospitalizations; the presence of invasive devices; the loss of integrity of normal skin and mucosal barriers; and, a more aged population. Immobility, bladder and bowel incontinence, and immunosenescence, often found in the elderly, are also associated with an increased risk of infection. Patients with diabetes mellitus, renal failure, chronic lung disease, chronic heart disease or immunosuppression as part of therapy for cancer, rheumatological conditions or inflammatory bowel disease are at increased risk of developing infections. In 1997/1998, 52\% of hospitalized patients in Canada were over 65 years of age, even though seniors only represented $12 \%$ of the population (36); it is likely that this figure will continue to increase over time. Monitoring of patient acuity scores in general medical wards has shown a marked increase in the severity of illness among patients admitted to these wards over the past two decades $(36,37)$. Success with outpatient therapy and constraints associated with a limited number of hospital beds means that only those

${ }^{1}$ Departments of Pathology and Laboratory Medicine, Medicine, and Microbiology and Infectious Diseases, Centre for Antimicrobial Resistance,

University of Calgary, Calgary, Alberta; ${ }^{2}$ Queen Elizabeth II Health Sciences Centre and Dalhousie University, Halifax, Nova Scotia

Correspondence: Dr JM Conly, Foothills Medical Centre, 1403-29 Street South, Calgary, Alberta T2N 2T9. Telephone 403-944-8222,

fax 403-944-1095, e-mail jconly@ucalgary.ca

Received and accepted for publication May 31, 2006 
patients with the highest burden of illness are now admitted to a general medical ward. Thus, the patients receiving care in general medical wards now commonly have multiple conditions that place them at increased risk of developing an infectious disease. The treatment of each admitted patient requires many interventions that have also been associated with increased risk of developing infections.

Other important factors that may influence the development of hospital infections include the HCW and levels of staffing. Considerable evidence (38-41) supports the belief that organisms may be carried from patient to patient via the unwashed hands of HCWs. The large variety of HCWs, including less skilled workers and part-time staff attending to patient needs, may result in inconsistent training and compliance with basic hygiene skills, such as handwashing, gloving, gowning and using aseptic techniques. Case control studies have demonstrated that the lack of familiarity with a required skill set in a specific work setting has been associated with an increased number of hospital-acquired infections. Several studies (42-48) have demonstrated that understaffing, and the educational level and skill of the health care practitioner are associated with the transmission of microorganisms and the development of nosocomial infections.

As noted previously, several factors related to the hospital environment may also contribute to an increased propensity for hospital-acquired infections and the transmission of antimicrobial-resistant pathogens, including the physical plant design, engineering controls (generally defined as sink placement, design of space to facilitate good hygiene practices, ease of handwashing, and the ability to maintain general environmental hygiene), the use of aseptic techniques and other infection control practices, and the host-HCW interaction (7). These design factors have taken on increasing importance in recent years with respect to the types of patients admitted to health care facilities and the degree of comorbid illnesses.

Recent data (7) from The Center for Health Design provide evidence to support hospital design and improved outcomes in patient safety (including HAIs) and quality of care. Over 120 studies linking HAIs to the environment were identified (7). A review of the citations indicated that the majority of studies identified were either related to an outbreak investigation or were of quasiexperimental design using before-after interventions, occasionally with sequential intervention to improve the epidemiological strength of the observation, and focused primarily on HAIs transmitted through either airborne or contact routes of transmission. A number of airborne routes of transmission were identified, including air filters, direction of air flow, air pressure, air exchanges per hour, humidity, and ventilation system cleaning and maintenance. Many of the outbreak investigations identified Legionella and Aspergillus species infections in immunosuppressed populations. Regarding the contact transmission route, several studies reviewed by Ulrich et al (7) have suggested that hand hygiene compliance may be improved by increasing the sink or waterless hand-sanitizing dispenser to bed ratio and by strategically placing sinks and waterless hand-sanitizing dispensers. In addition, these studies have suggested that the rates of HAIs spread through contact and airborne routes of transmission are lower in settings with single-bed rather than multibed rooms. The presence of common shared space and multibed rooms in hospital emergency departments, intensive care units, and hospital wards in Canada and several Asian countries during the
SARS outbreak are acknowledged to have hampered control efforts. A recent example of hospital design features that were associated with a reduction in HAIs can be found at Bronson Methodist Hospital in Kalamazoo, Michigan, where an 11\% decreased rate of HAIs was associated with the opening of new patient pavilions that featured private rooms and strategically located sinks (7). There are similar data from Canada. Compared with historical controls, a $70 \%$ decrease in the incidence density of AROs and hospital-acquired infections related to MRSA, VRE and C difficile over 18 months was found in a newly renovated general medical ward at Foothills Medical Centre in Calgary, Alberta, which had recently undergone extensive renovation and redevelopment of an existing footprint to create 28 private rooms (10 with negative air pressure capability) with wheelchair-accessible private washrooms, redundant handwashing stations, and extra space for both patients and caregivers ( $T$ Lye, Calgary Health Region, personal communication).

The rigorous application of evidence-based design can improve hospital environments in several spheres: the enhancement of patient safety by reducing HAIs, injuries from falls and medical errors; the elimination of environmental stressors, such as noise, that negatively affect outcomes and staff performance; and, the reduction of stress and promotion of healing by making hospitals more pleasant, comfortable and supportive for patients and staff alike. Ulrich et al (7) have made several recommendations to improve quality and safety. One suggestion involves the enhanced use of single rooms that can be adjusted to meet medical needs in a flexible manner and that improves patient safety by reducing patient transfers, decreasing the risk of nosocomial infections and improving staff communication with patients (in part related to facilitating patient privacy). They also recommended improving indoor air quality with well-designed ventilation systems and air filters to prevent hospital infections; using sound-absorbing ceiling tiles and carpeting to reduce noise in an effort to improve sleep patterns, reduce blood pressure and reduce rehospitalizations; providing better lighting and access to natural light to improve patient safety; creating pleasant, comfortable and informative environments with improved layouts, colour schemes, furniture choice and arrangement, floor coverings and curtains; and, providing informational material and displays, directional signage at key decision points, reassurance signs for long paths, and clear identification of rooms. Settings that help staff do their jobs would be expected to lead to greater staff satisfaction, which could also have a positive influence on patient outcomes. With the application of new design, construction and the judicious adaptation of engineering controls, the efficiency of patient care may be optimized with the potential to minimize adverse outcomes and costs. Hopefully, hospital planning teams will take into account the growing body of evidence regarding the need to optimize features to improve safety and minimize hospital-acquired infections.

\section{REFERENCES}

1. CDC and the Healthcare Infection Control Practices Advisory Committee (HICPAC). Guidelines for environmental infection control in health-care facilities: Recommendations of CDC and the Healthcare Infection Control Practices Committee (HICPAC). Morbidity and Mortality Weekly Report 52(RR-10), 1-42. <www.cdc.gov/mmwr/ preview/mmwrhtml/rr5210a1.htm > (Version current at June 6, 2006).

2. McDonald LC, Walker M, Carson L, et al. Outbreak of Acinetobacter spp. bloodstream infections in a nursery associated with contaminated aerosols and air conditioners. Pediatr Infect Dis J 1998;17:716-22. 
3. Kumari DN, Haji TC, Keer V, Hawkey PM, Duncan V, Flower E. Ventilation grilles as a potential source of methicillin-resistant Staphylococcus aureus causing an outbreak in an orthopaedic ward at a district general hospital. J Hosp Infect 1998;39:127-33.

4. Opal SM, Asp AA, Cannady BP Jr, Morse PL, Burton LJ, Hammer PG II. Efficacy of infection control measures during a nosocomial outbreak of disseminated aspergillosis associated with hospital construction. J Infect Dis 1986;153:634-7.

5. Loo VG, Bertrand C, Dixon C, et al. Control of construction-associated nosocomial aspergillosis on an antiquated hematology unit. Infect Control Hosp Epidemiol 1986;17:360-4.

6. Menzies D, Fanning A, Yuan L, FitzGerald JM. Hospital ventilation and risk for tuberculosis infection in Canadian health care workers. Canadian Collaborative Group in Nosocomial Transmission of TB. Ann Intern Med 2000;133:779-89.

7. Ulrich R, Quan X, Zimring C, Joseph A, Choudhary R. The role of the physical environment in the hospital of the 21st century: A once-in-a-lifetime opportunity. The Center for Health Design. <www.healthdesign.org/research/reports/physical_environ.php> (Version current at June 6, 2006).

8. Learning from SARS - Renewal of public health in Canada. 2003. Health Canada. <www.phac-aspc.gc.ca/publicat/sars-sras/naylor> (Version current at June 6, 2006).

9. Lessons from SARS. CMAJ 2003;168:1381, 1383.

10. Piaskowski P, Simpson K, Stewart M. Concurrent outbreaks of group-A streptococcal (GAS) invasive disease and influenza A. Canadian Journal of Infection Control 15, 4-5. 4-1-2000. (Abst)

11. Goob T. Fundamentals of a tuberculosis infection control program. Journal of Healthcare Safety, Compliance and Infection Control 1999;3:368-72.

12. Conly J. Clostridium difficile-associated diarrhea - The new scourge of the health care facility. Can J Infect Dis 2000;11:25-8.

13. Pfaller MA, Jones RN, Messer SA, Edmond MB, Wenzel RP. National surveillance of nosocomial blood stream infection due to species of Candida other than Candida albicans: Frequency of occurrence and antifungal susceptibility in the SCOPE Program. SCOPE Participant Group. Surveillance and Control of Pathogens of Epidemiologic. Diagn Microbiol Infect Dis 1998;30:121-9.

14. McGowan JE Jr, Tenover FC. Control of antimicrobial resistance in the health care system. Infect Dis Clin North Am 1997;11:297-311.

15. Simor AE, Ofner-Agostini M, Bryce E, et al; Canadian Nosocomial Infection Surveillance Program, Health Canada. The evolution of methicillin-resistant Staphylococcus aureus in Canadian hospitals: 5 years of national surveillance. CMAJ 2001;165:21-6.

16. Conly J. Antimicrobial resistance in Canada. CMAJ 2002;167:885-91.

17. Zoutman DE, Ford BD, Bryce E, et al; Canadian Hospital Epidemiology Committee; Canadian Nosocomial Infection Surveillance Program; Health Canada. The state of infection surveillance and control in Canadian acute care hospitals. Am J Infect Control 2003;31:266-72.

18. Morrison J; Health Canada, Nosocomial and Occupational Infections Section. Development of a resource model for infection prevention and control programs in acute, long term, and home care settings: Conference proceedings of the Infection Prevention and Control Alliance. Am J Infect Control 2004;32:2-6.

19. Woodward CA, Shannon HS, Cunningham C, et al. The impact of reengineering and the other cost reduction strategies on the staff of a large teaching hospital: A longitudinal study. Med Care 1999;37:556-69.

20. Robert J, Fridkin SK, Blumberg HM, et al. The influence of the composition of the nursing staff on primary bloodstream infection rates in a surgical intensive care unit. Infect Control Hosp Epidemiol 2000;21:12-7.

21. Fridkin SK, Pear SM, Williamson TH, Galgiani JN, Jarvis WR. The role of understaffing in central venous catheter-associated bloodstream infections. Infect Control Hosp Epidemiol 1996;17:150-8.

22. Daschner FD, Dettenkofer M. Protecting the patient and the environment - New aspects and challenges in hospital infection control. J Hosp Infect 1997;36:7-15.

23. Needleman J, Buerhaus PI, Mattke S, Stewart M, Zelevinsky K. Nurse staffing and patient outcomes in hospitals. Harvard School of Public Health. <www.haponline.org/downloads/NurseStaffPtOutcomes.pdf> (Version current at June 6, 2006).

24. Gravel D, Byrce E, Goldman C, et al. Nosocomial infections identified during a point prevalence survey within selected Canadian health care institutions. Abstracts of the 2003 Annual Scientific Meeting of the Society of Hospital Epidemiologists of America, Salt Lake City, Utah.
25. Centers for Disease Control and Prevention. Hospital infections cost US billions of dollars annually. <www.cdc.gov/OD/OC/MEDIA/ pressrel//r2k0306b.htm > (Version current at June 6, 2006).

26. Kim T, Oh PI, Simor AE. The economic impact of methicillin-resistant Staphylococcus aureus in Canadian hospitals. Infect Control Hosp Epidemiol 2001;22:99-104.

27. Birnbaum D; Canadian Committee on Antibiotic Resistance. Canadian Committee on Antibiotic Resistance. Antimicrobial resistance: A deadly burden no country can afford to ignore. Can Comm Dis Rep 2003;29:157-64.

28. Forster AJ, Asmis TR, Clark HD, et al; Ottawa Hospital Patient Safety Study. Ottawa Hospital Patient Safety Study: Incidence and timing of adverse events in patients admitted to a Canadian teaching hospital. CMAJ 2004;170:1235-40.

29. Forster AJ, Clark HD, Menard A, et al. Adverse events among medical patients after discharge from hospital. CMAJ 2004;170:345-9.

30. Haley RW, Culver DH, White JW, et al. The efficacy of infection surveillance and control programs in preventing nosocomial infections in US hospitals. Am J Epidemiol 1985;121:182-205.

31. Gilbert M, MacDonald J, Gregson D, et al. Outbreak of communityacquired (USA300) methicillin-resistant Staphylococcus aureus in persons with histories of drug use, homelessness and/or incarceration in Alberta, Canada. CMAJ 2006. (In press)

32. Pepin J, Valiquette L, Alary ME, et al. Clostridium difficile-associated diarrhea in a region of Quebec from 1991 to 2003: A changing pattern of disease severity. CMAJ 2004;171:466-72.

33. Loo VG, Poirier L, Miller MA, et al. A predominantly clonal multiinstitutional outbreak of Clostridium difficile-associated diarrhea with high morbidity and mortality. N Engl J Med 2005;353:2442-9.

34. Conly JM, Johnston BL. SARS: A tale of two epidemics. Can J Infect Dis 2003;14:147-9.

35. Health Canada, Population and Public Health Branch. (1999 July). Routine practices and additional precautions for preventing the transmission of infection in health care. Canada Communicable Disease Report, 25S4, 1-155. <www.phac-aspc.gc.ca/publicat/ccdr-rmtc/ 99vol25/25s4/index.html> Version current at June 6, 2006.

36. Canadian Institute of Health Information. Canadian Institute for Health Information. News release, Canada's elderly primary users of hospitals reports Canadian Institute for Health Information, 2000:1-4.

37. Baumgart AJ. Hospital reform and nursing labor market trends in Canada. Med Care 1997;35(10 Suppl):OS124-31.

38. Sochalski J, Estabrooks CA, Humphrey CK. Nurse staffing and patient outcomes: Evolution of an international study. Can J Nurs Res 1999;31:69-88.

39. Conly J, Johnston BL. The impact of health care restructuring on nosocomial infections and transmission of antimicrobial resistant organisms. Can J Infect Dis 2001;12:271-4.

40. Robert J, Fridkin SK, Blumberg HM, et al. The influence of the composition of the nursing staff on primary bloodstream infection rates in a surgical intensive care unit. Infect Control Hosp Epidemiol 2000;21:12-7.

41. Fridkin SK, Pear SM, Williamson TH, Galgiani JN, Jarvis WR. The role of understaffing in central venous catheter-associated bloodstream infections. Infect Control Hosp Epidemiol 1996;17:150-8.

42. Needleman J, Buerhaus PI, Mattke S, Stewart M, Zelevinsky K. Nurse staffing and patient outcomes in hospitals. Harvard School of Public Health. <www.haponline.org/downloads/NurseStaffPtOutcomes.pdf> (Version current at June 6, 2006).

43. Vicca AF. Nursing staff workload as a determinant of methicillin-resistant Staphylococcus aureus spread in an adult intensive therapy unit. J Hosp Infect 1999;43:109-13.

44. Yang KP. Relationships between nurse staffing and patient outcomes. J Nurs Res 2003;11:149-58.

45. Haley RW, Bregman DA. The role of understaffing and overcrowding in recurrent outbreaks of staphylococcal infection in a neonatal special-care unit. J Infect Dis 1982;145:875-85.

46. Hugonnet S, Harbarth S, Sax H, Duncan RA, Pittet D. Nursing resources: A major determinant of nosocomial infection? Curr Opin Infect Dis 2004;17:329-33.

47. Sochalski J. Is more better? The relationship between nurse staffing and the quality of nursing care in hospitals. Medical Care 2004:42(2 Suppl):II67-73.

48. Aiken LH, Clarke SP, Sloane DM, Sochalski J, Silber JH. Hospital nurse staffing and patient mortality, nurse burnout and job dissatisfaction. JAMA 2002;288:1987-93. 


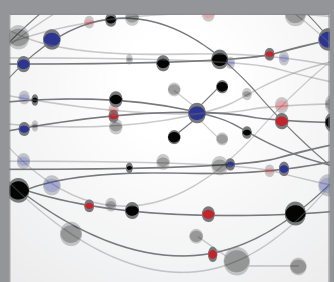

The Scientific World Journal
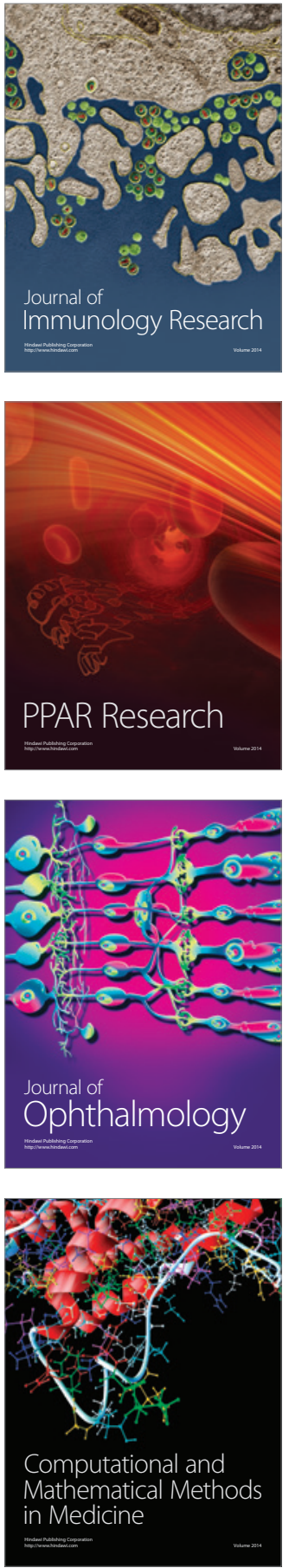

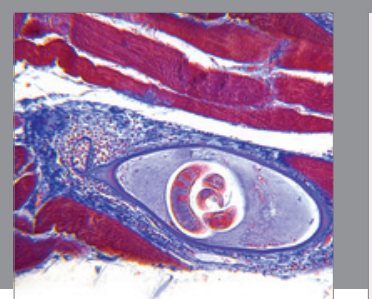

Gastroenterology Research and Practice

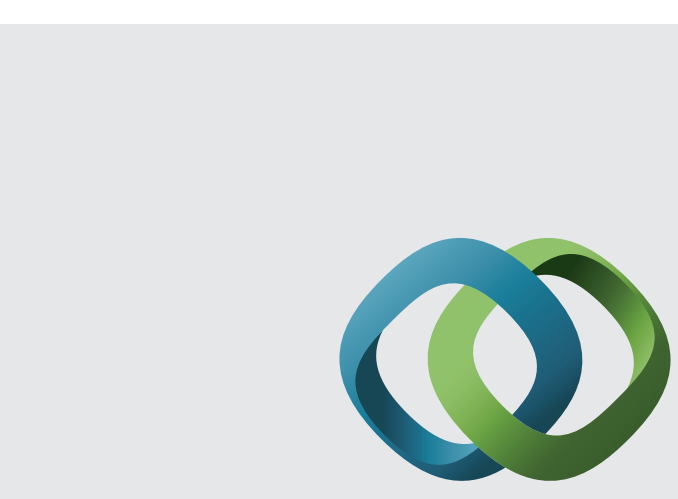

\section{Hindawi}

Submit your manuscripts at

http://www.hindawi.com
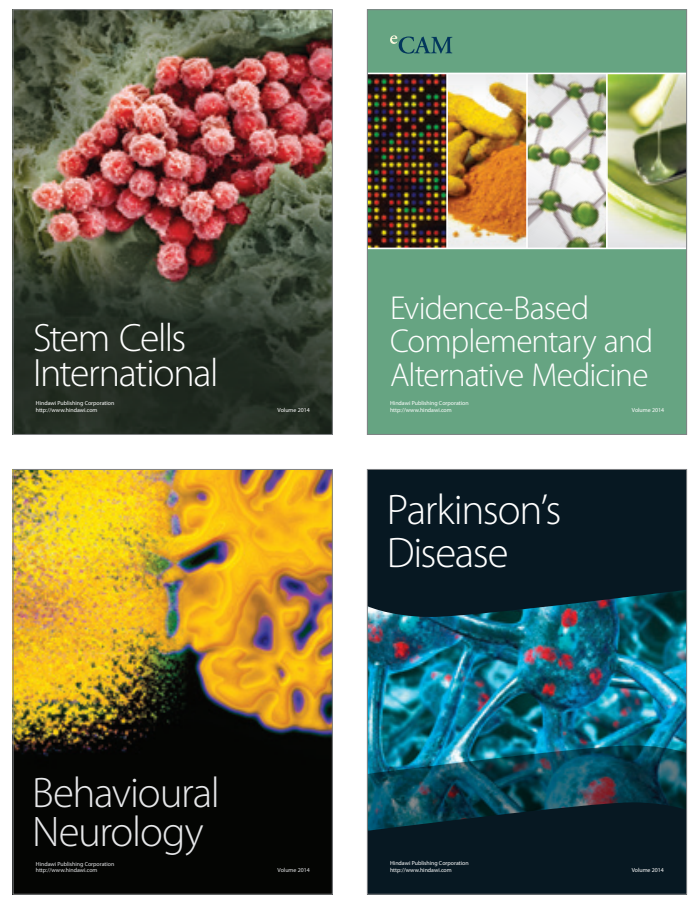
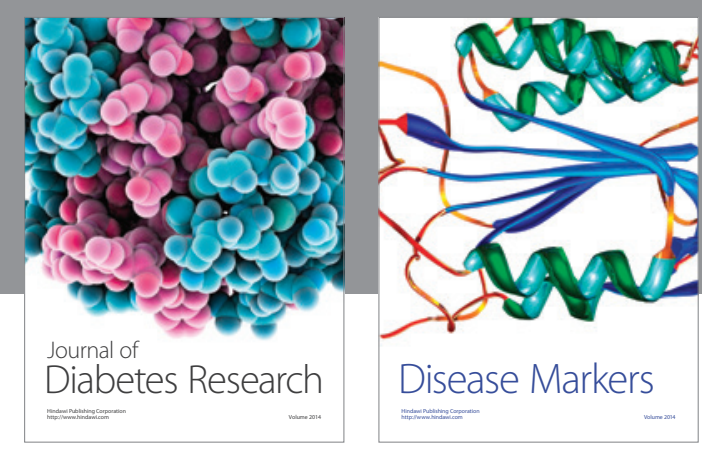

Disease Markers
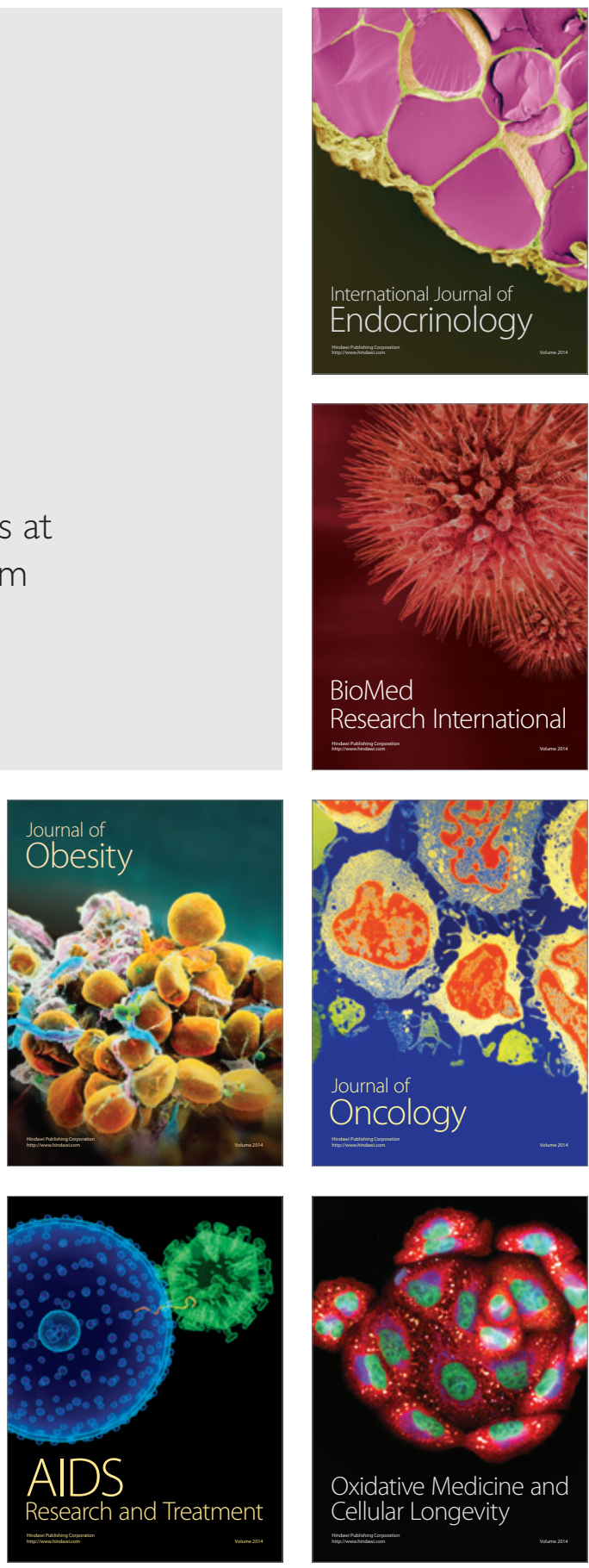